\title{
Research of the Starbucks' Ritual Sense and Strategy of Sales
}

\author{
Bojing Mi ${ }^{1, *, \dagger}$ Tianshu Zhang ${ }^{2, *, \dagger}$ Jingwen Zhang ${ }^{3,{ }^{*}, \dagger}$ Hantao Du ${ }^{4,{ }^{*} \dagger}$
}

\author{
${ }^{1}$ Bojing Mi, Central University of Finance and Economics \\ ${ }^{2}$ Tianshu Zhang, Beijing Institute of Graphic Communication \\ ${ }^{3}$ Jingwen Zhang, Auckland (NZ) Macleans College \\ ${ }^{4}$ Hantao Du, Capital University of Economics and Business \\ *Corresponding author.Email: author@example.com
}

${ }^{\dagger}$ These authors contributed equally.

\begin{abstract}
Starbucks has been leading the coffee market. The main reason is that in addition to products, Starbucks marketing model is also an important factor. We will promote Starbucks' brand awareness as a marketing strategy. This study uses a combination of first-hand and second-hand research methods. In the first-hand research, through interviews, we obtain the opinions of consumers and former Starbucks employees on some issues, and get some effective information. The study finds that Starbucks through their unique forms of expression to meet the audio-visual ceremony sense, environmental ritual sense, interactive ritual sense and corporate culture ritual sense, and jointly builds their brand sense of ritual, thereby promoting consumer trust in it and achieving the ultimate goal. There are still gaps in the brand ritual sense. We have made some definitions of brand ritual sense and perfected the research. In addition, through systematic analysis, this paper also provides some reference value for the marketing strategies of other coffee brands and how to attract consumers.
\end{abstract}

Keywords: Starbucks marketing strategy, Brand ritual sense, Starbucks' enterprise service model

\section{INTRODUCTION}

Starbucks is a multinational coffee shop chain in the United States and the largest coffee shop chain in the world. Founded in 1971, Starbucks Coffee Company is committed to ethically sourcing and roasting the world's highest quality arabica coffee. With more than 32,000 stores in 82 markets worldwide, Starbucks is the world's leading specialty coffee roaster and retailer. Standardization of coffee production and "light of luxury culture" brand publicity is Starbucks management features. In addition, Starbucks has created a culture called "the third space" (place for leisure and shopping). Starbucks use graceful flowing music, elegant and comfortable European furniture and other supporting facilities for the consumer to create a "light is luxury, fashion" culture atmosphere. Drinking coffee can make people feel a kind of life experience, while Starbucks has special pay attention to the environment to provide consumers with experience stores. It provides consumers with a place to chat, relax and drink coffee, so
Starbucks is successful. (Data source Baidu Encyclopedia - Starbucks introduction)

Recently, the topic "Starbucks Atmosphere Group" has become popular on various platforms. "Atmosphere Group" has attracted the attention of netizens, followed by the \# Starbucks Atmosphere Group \# has become a hot topic on Weibo. As of press time, the topic has been read over 170 million, and the number of discussions is 21,000 . "After careful consideration, we have decided to immediately recruit 30 people for the official atmosphere team. The recruitment period will be from December 21 to 27 , and the term will be one week," said Starbucks' official Weibo account. Many people also spend the whole day with their bags and laptops on their backs, while doing part-time jobs in the Starbucks atmosphere group. After all, is working in a coffee shop really not a distraction? Why do so many people like to work in coffee shops? The single environment of home or office, with its usual four walls, desks and chairs, is not soothing. At the coffee shop, even if you feel like you're working alone when you're wearing noise-cancelling headphones and 
staring at your computer screen, there's always something going on around you. I'm sure many of you have seen a group of people working while drinking coffee at Starbucks. Maybe it is because some friends think that working in Starbucks stores is very comfortable and quiet. The decoration style is dark, which gives people a sense of relaxation. Moreover, the quality of coffee is also very guaranteed, and the use of high-quality coffee beans has high requirements for quality. Usually, the ambient sound of a cafe falls around 70 decibels, which is the most suitable volume for work. On the other hand, less than 50 decibels or more than 85 decibels may keep the goddess of inspiration from coming. Starbucks fits these criteria, so many office workers have turned to the 'Starbucks Atmosphere Group' for inspiration. (Data source of Starbucks Atmosphere Group: Qianjiang Evening News - Hour News reporter Zhu Yao)

The proposal of Starbucks' diversification: Starbucks' transformation to diversify sales was actually a helpless move at first. In response to the increasingly saturated American coffee market. From 2008 to 2009, Starbucks' business in the United States severely declined, and its annual profits fell sharply due to the downturn in the US market. In June 2012, Starbucks had opened 17,400 stores around the world, of which 10,800 were Starbucks in the United States. The number of Starbucks stores in the United States has become saturated. Obviously, it is impossible to increase revenue by expanding stores. After analyzing the market, Starbucks discovered that only innovative new marketing models can awaken the enthusiasm and interest of the American people in Starbucks. Since 2012, Starbucks has been launching products that have nothing to do with coffee while selling coffee. From opening the first juice bar in Seattle to sell energy drinks, to now selling notebooks, coffee cups, key chains and other products, Starbucks has never stopped diversifying. Former Starbucks chairman and CEO Howard Schultz once said: Starbucks has never defined a strategy to prevent it from developing other businesses outside of its stores. In China, because of the expanding population and the pace of life is becoming more and more compact, coffee is no longer a necessity, not to mention the price of a cup of Starbucks coffee. If Starbucks wants to survive in the Chinese market, diversification is a necessary choice.

Research ideas: As the above analysis has mentioned a lot of information about the Starbucks, this paper will make a very detailed and meticulous analysis in a variety of areas belongs to the services of marketing strategy with strong ritual of Starbucks. Including of brand's wellknown operating philosophy

as the "third place" concept, the essay will put emphasis on researching the deep content of it. What's more, the sales strategy of Starbucks in the main products, the analysis of a great and fun form of promotion, as well as the forecast of the enterprise is taking for the next few years are also contained in this essay.

When researching the impact of brand's ritual marketing strategy of the market, we will combine the primary data (interview) and secondary data (literature analysis, commercial data analysis) to explore the question. This paper will lead to a combination of thematic research results and some new thinking.

The findings of this study can serve as a reference for firms seeking to improve the marketing effects of their services of marketing strategy through strong ritual of Starbucks.

\section{LITERATURE REVIEW}

Brand management is becoming more and more important. Our country is implementing brand strategy. The brand building of Starbucks has its own characteristics, which is worth learning from many enterprises. Unique positioning and effective transmission to employees and consumers, perfect education and training, to meet the multi-level needs of employees and customers -- material needs and psychological needs ${ }^{[1]}$. Experience is rapidly infiltrating into contemporary economy and becoming one of the main directions of economic development." Experience "is not the privilege of the elite class, but the psychological appeal of the common people. The products of Starbucks are not only coffee, but also through the carrier of coffee, a unique style is transmitted to customers. To a large extent, coffee consumption is a kind of consumption at the cultural level. Cultural communication requires that the environmental culture created by the coffee shop can infect customers, so that customers can enjoy and form a good interactive experience ${ }^{[2]}$. Starbucks is the only worldwide coffee company with a presence on four continents. Starbucks has deeply implanted its differentiated brand culture into the minds of customers, and its brand construction is worthy of our study and learning ${ }^{[3]}$.

Strategy of Sales. As for the marketing strategy of Starbucks, many scholars have raised different opinions, the most concentrated point of view is that Starbucks has gradually stabilized its position among the world-class coffee brands by using the strategy of "experiential marketing".

The proposition of Starbucks is that they do not sell coffee, but sell the unique experience of coffee ${ }^{[4]}$. This unique coffee experience includes emotional experience, atmospheric experience, sensory experience and social experience, which is exactly what makes Starbucks unique. "Experiential marketing" is how Starbucks, the coffee giant, does the world-known business.

Another scholar Wang $\mathrm{Xi}$ interpreted the marketing model of Starbucks from four aspects ${ }^{[5]}$, which are 
experiential marketing, brand marketing, cultural marketing, and localized marketing. In his opinion, Starbucks carries out experiential marketing by stimulating consumers' senses, emotions, thinking, actions, and associating with various rational and emotional factors by means of watching, listening, using and participating. Secondly, as for the brand characteristics of the enterprise, consumers can form a cognition of the brand and products of the enterprise through marketing means, which is a brand marketing. Cultural marketing is based on the product as the carrier, implant some cultural factors, such as the decoration of Starbucks stores, peripheral products, etc., trying to create a warm atmosphere to attract consumers and arouse resonance. In terms of localized marketing, he believes that Starbucks, as a world-class enterprise, is not only committed to developing its own culture when conducting multinational business, but also will appropriately combine the needs of different societies and cultures in different countries to make innovations and changes in products and services.

At present, the academic community is still actively exploring the marketing strategy of Starbucks, but there is no denying that the marketing method of Starbucks must be unique and irreplaceable for its leading position in coffee.

Brand Ritual Sense and Marketing Strategy. There is a certain number of researches between brand ritual sense and marketing strategy, probably divided into three categories," said Mulan sister, a scholar, the brand in marketing began to target consumers with high attention to social hot spots and dynamics, in the wave of the promotion is also willing to become participants, keen to publish new things on social media this psychology, through people's special consumption behavior ritual design to guide consumption. Creativity is always the original tool for brands and retailers to get consumer attention, and ritual "experiences" are the best incubators for attention. Scholar He Qi thinks that " Starbucks has made a new attempt to build a brand culture by building a sense of brand ritual in order to gain the favor of consumers and increase customer loyalty in the face of increasing competition. Scholar Yu Tianjiao believes that "in the current society, brands can cultivate consumers at the brand level of the sense of ritual, cultivate brand consumption habits." These ritual actions, in the minds of consumers to form consumer habits, strengthen consumer awareness of the differentiated image of products, Starbucks in the spring launch of cherry blossom cups, Christmas series of drinks and cups, with peripheral products for the brand added value, added to the brand consumption of the ceremony. Scene ritual sense is a kind of exquisite life embodiment, that is, to give consumers a certain space, time, emotion, emotion and other factors under the combined effect of selfsatisfaction. Starbucks provides consumers with a third leisure space, which greatly enhances the sense of ritual consumption. Ritual marketing is not only reflected in the product experience level, but also reflected in the brand marketing strategy level.

Literature Review. In the existing research, we can find that these studies focus more on some specific forms of marketing strategy, and the research on marketing strategy is often limited to some common and familiar marketing strategies, while some special marketing strategies based on a special case are lack of certain research. For example, there is a lack of research on the sense of brand ceremony. This paper focuses on making up for the gaps and deficiencies in this part of the content, taking Starbucks as the main research object, to explore the process and influence of Starbucks in the construction of brand ritual sense.

\section{CONCEPT COMBING OF BRAND RITUAL SENSE}

\subsection{Concept combing of brand ritual sense}

Ritual sense refers to ritualizing everyday actions in order to give them meaning is collectively known as ritualistic sense. In the context of psychology or behavior, the sense of ritual can be roughly described as the systematic repetitive behavior of individuals to selfsuggest in order to overcome anxiety about uncertainty. Ritual sense can be seen as the need to ritualize everyday behavior: to give a ritual meaning to an event through systematic repetition.

The function and value of ritual sense. The purpose of ritual sense is to increase the value of an event, enhance people's sense of control over life, distinguish people from things in an instant, and highlight human dignity.

\subsection{The Concept of Brand ritual sense.}

Brand ceremony feeling make simple is no longer a badge, a symbol, it transfer value, rich life, meet the emotional needs, it becomes convenient tools, understanding the world around you, therefore, the role of the brand more and more become the life, become a powerful value, more and more a sense of ritual brand, more attractive to customers, can arouse the enthusiasm of the customers heart, build strong relationships with customers, and resonate, visualization expression of goods also exist in the individual consciousness, brand by trade into a religion.

The importance, value and significance of brand ritual sense to brand development. Today is an era of abundant materials and flourishing personalized needs. Along with consumption upgrading, people's consumption concept has changed from functional satisfaction to emotional satisfaction, and the pursuit of higher psychological premium has been achieved. Under this new consumption 
pattern; The sense of ritual just meets this need. It makes product consumption not a simple monetary relationship, but an emotional exchange between users and brands. And this kind of behavior is the current fierce commercial market, brands increasingly look at. Regardless of the origin of the final source, one thing is clear: the "sense of ritual" is indeed increasingly an important manifestation of being. Especially when we are discussing the topic of how to carry out brand marketing, paying attention to the sense of ceremony may be becoming the marketing direction pursued by merchants. After all, making marketing have a sense of ceremony also ensures that marketing and brand can be more contacted and accepted. To appeal to consumers, brands have to give them a sense of being above me. It needs to provide me with something I don't have, or, more precisely, to make me something I'm not. It's not functional satisfaction, it's more psychosocial satisfaction. Therefore, the satisfaction of social psychology requires the brand to pay attention to the emotional needs of consumers. In holiday marketing, brands value emotional communication with users. Ritual sense, with emotion as the link, can help the brand to provide exposure, and quickly connect with the form of consumers. Especially in the era of mobile Internet, when the consumption pattern changes, the real sign of the end of consumption behavior is sharing diffusion, that is to say, the transmission of word of mouth. Therefore, it is of more realistic significance to think about how to rebuild the sense of ritual of the brand from this perspective.

Through the above definition and function of "sense of ritual" and "sense of brand ritual". Based on the specific practice of Starbucks, we find that Starbucks' brand sense of ceremony mainly includes four aspects: visual and visual sense of ceremony, environmental sense of ceremony, interactive sense of ceremony, and corporate culture sense of ceremony. In its Q1 2018 report, Starbucks reported revenue of more than $\$ 6$ billion. In Q1, U.S. revenue grew 7\% year-over-year to $\$ 4.3$ billion, but same-store sales grew only $2 \%$, thanks to 979 new stores opened in the past 12 months. In July last year, for the price of $\$ 1.3$ billion back to the Starbucks in China's Jiangsu area management (formerly run by unified group), which means that the 1300 stores in the east China market will be incorporated in the company has its own operating range, it can be seen that the brand sense of ritual shape is of great significance for the development of Starbucks. (Data source: Starbucks Annual Report)

\section{STRATEGY ANALYSIS OF STARBUCKS TO CREATE A SENSE OF BRAND CEREMONY}

\subsection{Shaping the Sense of Audio-Visual Ceremony}

The first Starbucks Brown logo came from a 16th century Scandinavian double tailed Mermaid. Later, Starbucks was merged by the daily coffee founded by Howard Schultz. After combining the green of the daily coffee trademark, the distinctive trademark was born. It is said that the founder used the mermaid to "lure customers to drink coffee". Although it is strange, the meaning is very commercial, and it is also one of the representatives of success.

The logo design of Starbucks gives consumers a simple, novel and overall feeling suitable for modern consumption. The logo with good visual impression seems to have become another symbol besides coffee. The growth of popularity has brought more macro cultural footprints - perhaps because the logo is made like a badge. After the investigation of Starbucks consumers, we can find that consumers have a deep impression on the logo. Now, when people talk about Starbucks, the double Mermaid logo of Starbucks comes to mind first. Starbucks has grasped the psychology that consumers pay attention to the logo, printed the logo on the ordinary cup and sold it at a high price to realize commercial realization

Most of Starbucks are dark green, with white sofas, wooden tables and chairs, dark brown walls, wall heaters, red brick sales desk, cool chairs and dark green umbrellas outside the store, and black metal tables and chairs. The overall light is mainly yellow, in order to create a harmonious atmosphere. The main purpose of the decoration design of Starbucks stores is to create a simple, warm, fashionable and approachable environment, so that customers can feel happy and relaxed after entering Starbucks, and enjoy a cup of coffee and a moment of peace.

Through the interview, we can find that most consumers like the environment of Starbucks very much, and the goal of Starbucks decoration has been completely realized. Most consumers say: after a long busy time, they go to Starbucks, order a cup of coffee, sit in a comfortable chair, and listen to relaxed music. They feel very comfortable and comfortable. Some office workers say that their favorite thing is to order a cup of coffee at Starbucks after work and relax in the shop. "Music is the most important thing in our 40 years of entrepreneurship, so we are also thinking about how to apply it in stores." Starbucks CEO Howard Schultz said. There are many kinds of music played in Starbucks stores, such as grassroots blues, soul, folk songs, rock and roll, country songs, classic jazz, lyric songs and so on. 


\subsection{Shaping the Sense of Environmental Ritual}

In the 1990s, Starbucks took the lead in introducing the concept of "third space" into its coffee shops. The third space refers to the environment between home and office, which is not only relaxing but also a public environment with high social performance and freedom.

Starbucks wants to create a harmonious environment that allows consumers to have a special release outside of their home and work place. In Starbucks stores, we often see some people sitting in front of the computer, a cup of coffee, a dessert at hand, while they work, while enjoying the cozy afternoon tea time; Sometimes, we can also see some people sitting by the window, holding a cup of coffee in a daze and meditating... Through the concept of "third space", Starbucks wants to seize the third space of consumers with this intermediate state of non-home and non-office. Many people use coffee shops as the best place to relax outside their home or work space, or as a place to socialize with friends. In a network of the hot issues in the second half of 2020, Starbucks had a brief experience activity, the main purpose is to recruit volunteers as a "group" atmosphere, in Starbucks stores create a comfortable casual work, study atmosphere, to encourage other consumer behavior, and strengthen the consumer for the recognition of the concept of "the third space". In the interview, we found that consumers were the connotation of "the third space" for Starbucks, though not very attention, for they are very comfortable but Starbucks experience, it also proves that to some extent, on the basis of the concept of "the third space" of the environment sense of ritual in the consumers' mind subtly was strengthened. On this basis, consumers will be more willing to choose Starbucks as their daily life, work and leisure relaxation choice. When customers come to Starbucks and have the most direct perception of the atmosphere in the store, it has a significant positive impact on customer's repurchase intention.

The tables and chairs in Starbucks stores are also very distinctive and consistent to a large extent. The seats in Starbucks stores are usually wooden chairs, stools and sofas. Wooden chairs and stools are mostly light brown and dark brown, with clear texture and soft color. Combined with the warm light lamps in Starbucks stores, they can create a warm and comfortable atmosphere. Sofa is coriaceous more, simple sense is exquisite, appearance is dignified have grade, suit a few occasions such as business negotiation very much. The design of tables and chairs in Starbucks not only conforms to people's aesthetic needs in appearance, but also conforms to the principle of ergonomics in structure. Both the height and the materials are very specific. For example, compared with the wooden chairs and stools in Starbucks, the sofa not only has soft bags and backrests, but also has a lower height to create a comfortable and relaxed experience. Such humanized design of Starbucks tries to provide consumers with a good experience in a variety of scenarios. To some extent, it also increases customers' stay time in the store, thus improving consumers' consumption level in the store.

Environmental design is a means for enterprises to achieve the effect of serving customers by shaping the environment and atmosphere of the store. In the process of environmental design, customers can perceive and perceive the connotation of the products and services of enterprises, and also determine their staying time and shopping mood, thus influencing their consumption decisions. The ritual sense created by the environmental design of Starbucks stores will make consumers feel that here will always be a third space where people can accompany or enjoy life alone.

\subsection{Shaping the sense of interactive ritual}

Starbucks' peripheral products and activities in recent years have been a major part of shaping its sense of ceremony, and Starbucks' sense of interaction is representative and characteristic of the following.

First, peripheral products, in 2019, Starbucks cat claw cup led to a boom, quickly popular network, people have rushed to buy. Starbucks cat claw cup cute shape, consumers have a strong desire to buy, at all costs to snap up. Starbucks cat claw cup for consumers is to spread the following points, first of all through these peripheral products, improve Starbucks brand awareness, many people may not know Starbucks before, but the trend of cat claw cup, in the network, social media frequently appear, so that more people know Starbucks, or have the will to learn more about the brand, so greatly enhance Starbucks brand recognition. Every Christmas Starbucks introduces a special coffee cup, which has been going on since 1997. In addition to Christmas, Starbucks will also launch a limited number of coffee paper cups during the special holidays each year, through special holidays, special products, so that consumers have a brand memory of the brand. Second, for older customers, their brand loyalty can be increased. When a consumer is passionate about a brand, every time the brand launches a new peripheral product, there is a desire to buy or an interest in learning about the new product. Scholar Chen Honghao believes that "Starbucks peripheral products, in fact, more on behalf of Starbucks and fans between a sense of ceremony, far beyond the value of the surrounding products themselves." ${ }^{[9]}$ In addition, the introduction of peripheral products is itself a reward for loyal consumers, is a means to enhance brand attachment. Because loyal consumers have a high degree of good feeling and recognition of the brand, the introduction of surrounding products can improve their brand viscosity. "[9] In addition, Starbucks' rich and characteristic activities create a sense of interaction. Buy an accompanying cup at a Starbucks store, then bring a cup to Starbucks for coffee to take away directly from your own cup and enjoy a free cup. Every year on April 2nd, Earth Day, in order to 
promote environmental protection, customers can bring their own cups, containers, Starbucks can be filled free of charge. Starbucks continues to carry out rich and interesting activities, so that customers participate in the at the same time, in-depth customer life, to promote the brand, promote positive energy, and formed a Starbucks "interactive sense of ceremony." Starbucks through a variety of peripheral and activities, and customers fully interactive contact, jointly promote, improve and improve the brand.

\subsection{Shaping the Sense of Corporate Culture Ritual}

Starbucks' sense of ceremony is shaped not just by interaction with consumers, but by excellent design from the outside. Starbucks also has a sense of ceremony in the construction of corporate culture within the company. On-the-job Starbucks employees, including interns, have their own brand names, as well as "partner coupons" and other benefits, enterprises focus on all employees to establish equal channels of communication, to encourage employees at Starbucks to achieve self-realization. At the spiritual level, Starbucks set up a "black apron" coffee master, "brown apron" coffee master and other honors, to add employee motivation; At the material level, the full year of joining Starbucks can obtain coffee bean stock holding Starbucks, you can apply for a home purchase fund, difficulties can apply for a "star fund." It can be said that Starbucks through the ceremony of the internal shaping of its staff team is very united, cohesive, their enthusiasm for work into quality services, thereby increasing productivity, in the brand reputation and revenue have been improved ${ }^{[7]}$. We asked employees who had worked at Starbucks, who believed that the company's corporate culture gave them a good working environment and that multiple benefits could empower them. In addition, they promote the brand by giving friends preferential benefits and introducing the benefits of Starbucks. Have a good, work-keen team of employees, the output of products, results will not be bad. Starbucks through the construction of the internal corporate culture ritual sense, completed the internal consolidation, improve, while achieving to make consumers more satisfied with the consumer experience, brand more perfect.

\section{CONCLUSION AND DISCUSSION}

Through the previous research, this paper has drawn three conclusions. (1) The research strategy of Starbucks' brand ritual sense has brought great effects on the development, scale improvement and performance of the enterprise. (2) Through the analysis and exploration of Starbucks' marketing strategy and the interview of consumers, we can conclude that Starbucks' marketing strategy mainly focuses on four aspects: the visual and visual sense of ritual, environmental sense of ritual, interactive sense of ritual, corporate culture sense of ritual; (3) Starbucks uses its four sense of ritual to bring special and profound experience to consumers. It through the simple atmosphere of the enterprise LOGO design, so that consumers have a strong impression of the brand. (4) The store decoration and music are used to make consumers feel the warm and comfortable atmosphere, so that consumers can feel the service of Starbucks visually and audibly. Starbucks adheres to the concept of "third space" in the creation of the sense of environmental ceremony. It has done enough homework in the design of seats and other aspects of stores, trying to adapt to the different needs of consumers, and trying to create a third comfortable area besides home and workplace for consumers. In the operation process of Starbucks, a variety of peripheral products, online and offline activities have also created a positive impact on its development. Enterprises strengthen consumers' sense of brand identity through multi-dimensional peripheral products, and regularly hold interesting activities to enhance the brand's market influence, thus creating a sense of interactive ceremony. Starbucks not only pays great attention to serving consumers, but also pays great attention to internal culture construction and personnel training. The company strives to establish equal communication channels for all employees and encourages employees to complete self-actualization in Starbucks. A good working environment and a variety of benefits can also enhance their working motivation. The positive role of corporate culture ritual in the growth process of Starbucks is also worth paying attention to.

Next, this paper will make the following evaluation on the research: there are still some shortcomings in the data collection. On the one hand, the first-hand data (interviews) do not cover the consumers of all social strata. On the other hand, the collection of secondary data is not comprehensive, so there may be some deviation in theory. Even though there are some shortcomings in this paper, it still has deep research significance.

There is a big gap in the research of corporate brand ritual sense in academic circles. This paper introduces and analyses the brand awareness, gives a specific definition of "brand ritual sense" after combining with the specific enterprise Starbucks, lists four parts of "brand ritual sense" of Starbucks, and completes the research of brand ritual sense in the theoretical level. In addition, this paper systematically analyses the specific practice of four kinds of ritual sense (audio-visual ritual sense, environmental ritual sense, interactive ritual sense, corporate culture ritual sense) in Starbucks and how Starbucks affects consumers through these four kinds of ritual sense. This paper provides a reference for Starbucks to further promote the marketing strategy of brand ritual sense, and also makes a certain contribution for other coffee brands to build a trust bridge with consumers. 


\section{REFERENCES}

[1] Hongxia Wu. Study on Brand Construction of Starbucks [J]. Journal of Taiyuan University, 2009, 10(1):50-54. F719.3; F273.2

[2] Runrun Han. Analysis of Starbucks Brand Building [J]. Market Modernization, 2008, 000(006):132. F717

[3] Yan Zhan. Brand Construction of Starbucks [J]. Theoretical Review, 2012(01):59-60.

[4] Xinrui Zhang. Marketing Strategy Analysis of Starbucks (China) [D]. Jilin University, 2014. F274; F719

[5] Xi Wang. Analysis of Starbucks' Marketing Strategy in China $[\mathrm{J}]$. Chinese Collective Economy,2016(12):49-50. F274;F719.3

[6] Mulan. Analysis of the underlying logic behind the marketing strategy of "ritual sense" of new consumer brands [OL]. Mad Men,2020

[7] Qi He. On the Marketing Strategy of Starbucks Brand Ritual Sense [D]. Capital University of Economics and Business, 2020:84-85. F719.3;F273.2;F274

[8] Tianjiao Yu. Phenomenal Topic -- Marketing Enlightenment behind "The First Cup of Milk Tea in Autumn" [D]. Suzhou Vocational Information Technology College, 2020:3-4. F274

[9] Honghao Chen. The promotion effect of peripheral products on brand intangible assets [A]. School of Media, Qufu Normal University: 166-167.F273.2; F719.3 